\title{
Hospital admissions among people who inject opioids following syringe services program implementation
}

\begin{abstract} based in Miami-Dade County. $(p=0.0034)$. on future hospital admission and mortality.

\section{Introduction}

In 2018, the Centers for Disease Control and Prevention announced drug overdose mortality hit a record high, with at least 70,237 Americans dying from an overdose [1]. The impact of the overdose crisis is felt heavily in Florida: opioid-related deaths increased $35 \%$ between 2015 and 2016 statewide [2]. Heroin-associated deaths in Miami-Dade County rose $826 \%$ between 2011 and 2016 [2]. As Miami-Dade County consistently ranks first in HIV incidence nationwide, implementation of
\end{abstract}

Background: Syringe services programs (SSPS) are an evidence-based harm reduction strategy that reduces dangerous sequelae of injection drug use among people who inject drugs (PWID) such as overdose. SSP services include safer injection education and community-based naloxone distribution programs. This study evaluates differences in overdose-associated hospital admissions following the implementation of the first legal SSP in Florida,

Methods: We performed a retrospective analysis of hospitalizations for injection drug-related sequelae at a county hospital before and after the implementation of the SSP. An algorithm utilizing ICD-10 codes for opioid use and sequelae was used to identify people who inject opioids (PWIO). Florida Department of Law Enforcement Medical Examiners Commission Report data was used to analyze concurrent overdose death trends in Florida counties.

Results: Over the 25-month study period, 302 PWIO admissions were identified: 146 in the pre-index period vs. 156 in the post-index period. A total of 26 admissions with PWIO overdose were found: 20 pre-index and 6 post-index

Conclusions: Declining overdose-associated admissions among PWIO suggests early impacts following SSP implementation. These results indicate a potential early benefit of SSP that should be further explored for its effects

Keywords: Syringe services program, Take-Home Naloxone, Overdose, Opioid epidemic

\footnotetext{
* Correspondence: kashabornstein@med.miami.edu

${ }^{1}$ University of Miami Miller School of Medicine, Miami, USA

Full list of author information is available at the end of the article
}

evidence-based HIV prevention coupled with overdose 37 prevention was imperative [3]. 38

In 2016, Florida enacted the Infectious Disease Elimin- 39 ation Act, allowing a pilot syringe services program 40 (SSP) but restricted to operate only in Miami, Florida: 41 the University of Miami IDEA SSP. The World Health 42 Organization, the Centers for Disease Control, and the 43 United Nations have found SSPs to be cost-effective in 44 reducing infectious disease burden [4-6]. In the year fol- 45 lowing the establishment of IDEA in Miami, approxi- 46 mately 518 PWID enrolled in services, and 795 kits of 47 two $4 \mathrm{mg}$ dose naloxone were distributed to participants. 48 In addition to sterile needles and injection supplies, 49

C C The Author(s). 2020 Open Access This article is licensed under a Creative Commons Attribution 4.0 International License, which permits use, sharing, adaptation, distribution and reproduction in any medium or format, as long as you give appropriate credit to the original author(s) and the source, provide a link to the Creative Commons licence, and indicate if changes were made. The images or other third party material in this article are included in the article's Creative Commons licence, unless indicated otherwise in a credit line to the material. If material is not included in the article's Creative Commons licence and your intended use is not permitted by statutory regulation or exceeds the permitted use, you will need to obtain permission directly from the copyright holder. To view a copy of this licence, visit http://creativecommons.org/licenses/by/4.0/ The Creative Commons Public Domain Dedication waiver (http://creativecommons.org/publicdomain/zero/1.0/) applies to the data made available in this article, unless otherwise stated in a credit line to the data. 
IDEA-SSP participants are provided with education on safer injection practices. This education includes instruction on the use of tester shots, using drugs with trusted friends, awareness of locations of previous overdoses, and unusually potent or otherwise toxic effects of commonly used drugs [7].

Importantly, SSP services include community distribution of take-home naloxone kits [8]. Take-home naloxone is an effective strategy for mitigating poor overdose outcomes as it reduces the time to administration versus activation of emergency medical services [9]. Community naloxone distribution removes barriers to naloxone access, a critical feature for populations that experience significant hesitation when seeking medical care, partially due to uninsured status, systemic bias, and stigma associated with drug use. PWID are often first responders to overdoses and reverse an overwhelming majority of community overdoses. A national survey from 1996 to 2014 reported over 26,400 overdose reversals with PWID conducting $82.8 \%$ of reversals [10]. Other research shows that PWID deploy take-home naloxone nearly ten times as frequently versus laypersons who do not use drugs-emphasizing the need to prioritize PWID in naloxone distribution efforts [11].

Multiple systematic reviews have found take-home naloxone programs to be both safe and effective, leading to increased survival rates among participants as well as decreases in community overdose mortality rates [12-14]. Although systematic analyses have found take-home naloxone programs are effective in reducing overdose deaths among participants, few studies assess the impact of take-home naloxone programs on hospitalizations [13-15]. We present a study analyzing early effects of the IDEA-SSP on the incidence of opioid overdoseassociated admissions at a county safety-net hospital in south Florida.

\section{Methods}

We conducted a 25-month retrospective review of hospitalized patients' data at Jackson Memorial Hospital (JMH), a public hospital in Miami, Florida, that serves people without regard for insurance status. The period of review encompassed December 1, 2015, to January 1, 2018. JMH is the only safety-net hospital in Miami-Dade County and is within a half-mile proximity of the IDEASSP. Data were separated into two periods, with December 1, 2016-the establishment of the IDEA-SSP —as an index date. To increase the specificity of the query, data from December 1, 2016, to January 1, 2017, was excluded to allow time for sufficient community enrollment. An algorithm used by Tookes et al. was adapted using International Classification of Diseases, Tenth Revision (ICD-10) codes to query the JMH electronic discharge and billing records for patients aged 18-85 (see
Supplemental Table 1) [16]. A combination of ICD-10 103 codes for opioid use and injection-related infections 104 (IRI) was used to identify people who inject opioids 105 (PWIO). Opioid codes included ICD-10 diagnoses re- 106 lated to opioids (see Supplemental Table 2). IRI included 107 endocarditis, bacteremia/sepsis, osteomyelitis, abscesses, 108 and/or cellulitis diagnoses.

Medical records were abstracted for demographic information, length of stay (LOS), insurance status, and discharge status. Additionally, we independently analyzed publicly available Florida Department of Law Enforcement Medical Examiner Commission reports from 2012 to 2017 to identify regional and statewide trends in opioid-related mortality to compare to local findings (Fig. 1).

\section{Analysis}

Descriptive statistics and frequency distributions for demographics, insurance status, and hospital use variables were utilized. Hospital use variables included discharge status and LOS for each hospitalization. Categorical data were described with numbers and percentages. Comparisons between pre- and post-index in frequencies of clinical and social demographic characteristics were analyzed by chi-square or Fisher's exact test. The chi-square test and Fisher's exact test can assess for independence between two variables when the comparing groups are independent and not correlated. Fisher's exact test was used for the analysis of demographic factors including race, age in year, and insurance status. Chi-square was used for the analysis of PWID overdoseassociated admissions. Because some continuous variables, such as age and LOS, were not normally distributed, the Wilcoxon rank-sum test was used for the comparisons. The results were reported as median and interquartile range. All analyses were performed in SAS 9.4 (SAS Institute Inc., Cary, NC).

\section{Results}

Three hundred two PWIO admissions were identified: 146 pre-index vs. 156 post-index $(p=0.12)$ (Table 1$)$. Race, sex, age, and insurance did not differ across preand post-index cohorts. Only $3 \%$ of PWIO had private insurance across the 2-year timespan. Approximately $60 \%$ of PWIO were uninsured, with no significant difference between cohorts $(p=0.88)$. Hospital mortality rates were not significantly different between the pre- and post-index cohorts. Nine (3\%) patients died during the hospital stay as determined by an "expired" discharge status: five pre-index vs. four post-index $(p=0.74)$.

\section{Overdose sequela}

Overdose-associated admissions significantly changed in 152 the post-index cohort vs. the pre-index cohort. In the 153 
Fig. 1 Opioid-caused deaths in select Florida counties 2012-2017

\section{Opioid-Caused Deaths in Select Florida Counties}

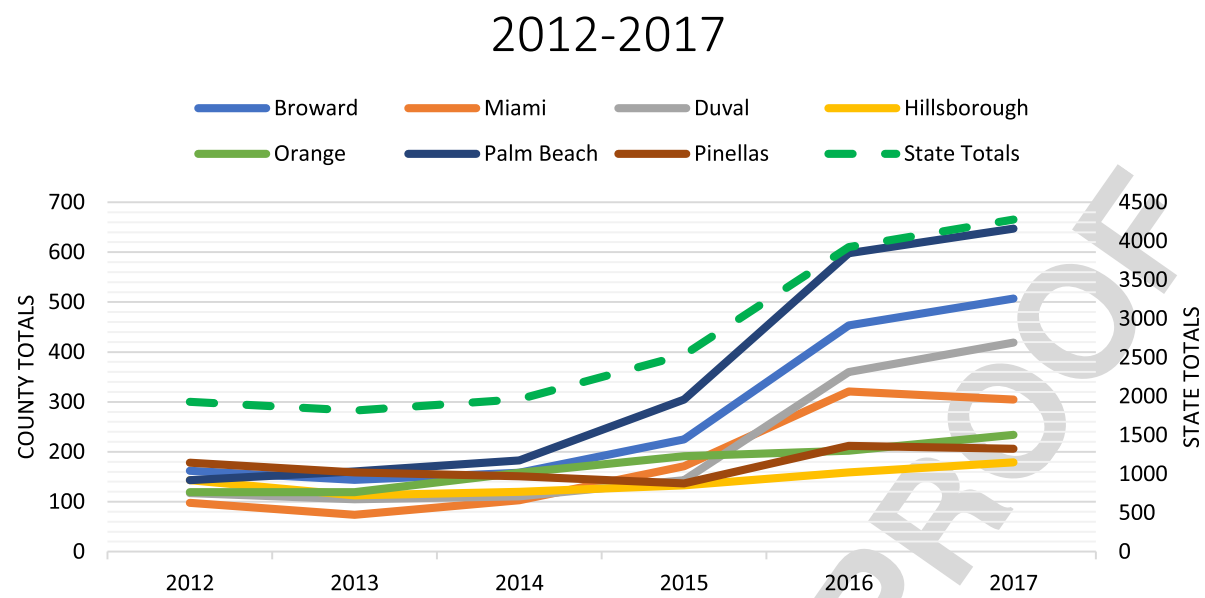

t1. 1

$\mathrm{t} 1.2$

$\mathrm{t} 1.3$

t1.4

t1.5

t1.6

t1.7

$\mathrm{t} 1.8$

t1. 9

t1. 10

t1.11

$\mathrm{t} 1.12$

t1.13

t1. 14

$\mathrm{t} 1.15$

t1.16

$\mathrm{t} 1.17$

t1.18

t1. 19

t1. 20

t1.21

$\mathrm{t} 1.22$

$\mathrm{t} 1.23$

t1. 24

$\mathrm{t} 1.25$

$\mathrm{t} 1.26$

t1.27

$\mathrm{t} 1.28$

Table 1 PWIO demographics

\begin{tabular}{|c|c|c|c|}
\hline & Pre-index, $n=146 ; \#(\%)$ & Post-index, $n=156 ; \#$ (\%) & $\overline{p \text { value }}$ \\
\hline Biological sex & & & 0.46 \\
\hline Male & $103(70.6)$ & $103(66.0)$ & \\
\hline Female & $43(29.5)$ & $53(34.0)$ & \\
\hline
\end{tabular}

Race

$118(80.8)$

27 (18.5)

$1(0.30)$

$124(79.5)$

Black

Others

29 (18.6)

$3(1.9)$

65 (44.5)

57 (36.5)

0.16

$81(55.5)$

$99(63.5)$

\section{Age in years}

$22(15.1)$

47 (32.2)

30 (19.2)

30-39

$36(24.7)$

47 (30.1)

30 (20.6)

48 (30.8)

50-59

$9(6.2)$

20 (12.8)

5 (3.2)

2 (1.4)

$6(3.9)$

Insurance status
$85(58.2)$
$31(21.2)$
24 (16.4)
5 (3.4)
$1(0.7)$
4
5 (3.4)
$20(13.7)$

95 (60.9)

Medicaid

34 (21.8)

21 (13.5)

4 (2.6)

2 (1.3)

0.14

4 (2.6)

0.74

PWIO overdose-associated admissions

$6(3.9)$ 
154 pre-index cohort, $14 \%$ of admissions involved an over155 dose diagnosis, vs. $4 \%$ in the post-index cohort $(p=$ 156 0.0034).

\section{Florida opioid-caused deaths}

158 State medical examiner findings demonstrated overall 159 increasing opioid-related deaths in Florida between 2010 160 and 2017. From 2014 to 2016, opioid-caused deaths in161 creased. The rate of increase declined from 2016 to 2017 162 except in Pinellas and Miami-Dade counties, where 163 opioid-related mortality decreased.

\section{Discussion}

165 Opioid-caused deaths increased in Florida following le166 gislative efforts to close "pill mills" in 2012, with result167 ing increases seen in counterfeit opioid pills and heroin 168 use [15]. This data explores opioid epidemic-related 169 morbidity and mortality in south Florida through the 170 lens of hospital admissions following the implementation 171 of IDEA-SSP. With the introduction of fentanyl and 172 high-potency analogues into the drug supply, sharp in173 creases in opioid mortality were seen statewide between 1742014 and 2016 [2, 17]. Given the heretofore unmitigated 175 statewide overdose crisis, it would be expected that hos-

176 pital data would reflect regional trends of increasing 177 overdose-associated admissions. However, following SSP 178 implementation, while the number of PWIO in our co179 hort did not change significantly, overdoses reported in 180 PWIO decreased significantly. The temporal association 181 suggests that the IDEA-SSP community distribution of 182 take-home naloxone may have produced early effects in 183 mitigating overdose-associated morbidity and mortality.

184 Several statewide opioid epidemic interventions were 185 implemented before and directly following the study 186 period, including a concerted law enforcement effort to 187 close "pill mills" [17]. However, these statewide policies 188 should theoretically affect all counties equally and thus 189 do not temporally explain Miami-Dade's decline in over-

190 dose deaths as reported by the Florida Department of

191 Law Enforcement Medical Examiners Commission (Fig.

192 1). During the study period, the IDEA-SSP distributed

193795 naloxone kits to participants and 387 reversals were

194 reported. Between 2016 and 2017, opioid-related mortal-

195 ity in Miami-Dade County declined 5\%, from 321 deaths

196 to 305 deaths. Similar declines were not seen in neigh-

197 boring counties. Considered together, these data suggest

198 early impacts of the first legal SSP in the state, operating

199 in Miami-Dade County.

200 More low-barrier SSPs are needed across Florida to in201 crease naloxone access among PWID and reduce state202 wide opioid-related morbidity and mortality. Due to 203 negative experiences PWID have when receiving services 204 in traditional health care settings, they may be less likely 205 to visit such settings to access naloxone, highlighting the importance of establishing naloxone distribution pro- 206 grams in low-barrier settings where PWID may feel 207 more comfortable-namely SSPs and other harm reduc- 208 tion modalities. Recent modeling simulating the impact 209 of 13 naloxone distribution modalities on overdose 210 deaths estimated expanding naloxone distribution 211 through a single SSP can reduce a community's overdose 212 deaths by $65 \%$ [18].

Limitations to this study exist. The ICD-10 does not have diagnosis codes for injection drug use or sequelae. This study relied on a novel ICD-10 adaptation of an ICD-9-based algorithm using codes for drug use and infectious consequences [16]. Additionally, the stigma associated with injection drug use remains widespread, and patients may not have reported use, resulting in under-documentation. Most importantly, our data do not imply causality between the establishment of the SSP and the decrease in opioid-associated admissions. Previous epidemiologic evaluations of SSPs describe lag times between community SSP implementation and decline in chronic infections [19]. An analysis of HIV rates among PWID in Baltimore only noted a significant decline after 5 years of increasing SSP service coverage, with sustained decline demonstrated thereafter [19]. Future research should explore longitudinal effects of the IDEA-SSP.

Despite these limitations, this study reveals a significant decrease in overdose-associated admissions among PWIO at a county safety-net hospital following the implementation of the IDEA-SSP in the setting of the contemporary Florida overdose crisis. Taken alongside medical examiner data, this study demonstrates trends of decreasing opioid overdose-related morbidity and mortality in Miami-Dade County. SSPs and take-home naloxone may impact the number of overdose-associated hospital admissions and warrant further study.

\section{Supplementary information \\ Supplementary information accompanies this paper at https://doi.org/10. 1186/s12954-020-00376-1. \\ Additional file 1: Supplementary Table 1. JMH PWIO. This data consists of the 302 admission of people who inject opioids that we analyzed in this manuscript. \\ Additional file 2: Supplemental Table 2. JMH PWIO ICD-10 Codes. This table contains the complete list of ICD-10 codes used for inclusion in the study as described in the Methods section.

Abbreviations

IDEA-SSP: University of Miami IDEA Syringe Services Program; PWID: People who inject drugs; JMH: Jackson Memorial Hospital; ICD-10: International Classification of Diseases, Tenth Revision; IRI: Injection-related infections; PWIO: People who inject opioids; LOS: Length of stay

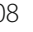
tio , 212 24 215 216 217 218 219 220 221 222 223 224 225 226 227 228 229 230 231 232 233 234 235 236 237 238 239 240 241 
262 and Stephanie Moody-Geissler for the support with the epidemiological 263 analysis.

\section{Authors' contribution}

$265 \mathrm{~KB}, \mathrm{AC}, \mathrm{AM}, \mathrm{HT}$, and JES all contributed to the design and interpretation of 266 the study. HL and TB performed the statistical analysis. KB and AC were the

267 major and equal contributors in writing the manuscript, aided by $A M, T B, H T$,

268 and JES. The author(s) read and approved the final manuscript.

\section{Funding}

270 We are extremely grateful for the grant support from the Infectious Diseases

271 Society of America through their Medical Scholars Program. We thank the

272 Miami Center for AIDS Research (P30Al073961) for the statistical support.

273 Research reported in this publication was supported by the National Cancer

274 Institute of the National Institutes of Health under Award Number

275 P30CA240139. The content is solely the responsibility of the authors and

276 does not necessarily represent the official views of the National Institutes of

277 Health.

278 Availability of data and materials

279 The de-identified dataset is available as Supplementary Table 1. Florida De280 partment of Law Enforcement Medical Examiners Commission Reports are

281 publicly available data.

282 Ethics approval and consent to participate

283 The study was approved by the University of Miami Institutional Review

284 Board (IRB \#20180242) and the Jackson Health System Clinical Research

285 Review Committee. Informed consent was not obtained from participants,

286 and a consent waiver was granted. Data were de-identified prior to analysis.

287 Consent for publication

288 Not applicable

289 Competing interests

290 The authors declare that they have no competing interests.

291 Author details

292 'University of Miami Miller School of Medicine, Miami, USA. ${ }^{2}$ Department of

293 Medicine, University of Miami Miller School of Medicine, Miami, USA.

$294{ }^{3}$ Department of Public Health Sciences, University of Miami Miller School of

295 Medicine, Miami, USA. ${ }^{4}$ Florida Department of Children and Families Office of

296 Substance Abuse and Mental Health, Tallahassee, USA.

299 References

300 1. Scholl L, Seth P, Kariisa M, Wilson N, Baldwin G. Drug and opioid-involved

301 overdose deaths - United States, 2013-2017. MMWR Morb Mortal Wkly Rep.

$302 \quad$ 2018;67(5152):1419-27.

303 2. Commission ME. Drug identified in deceased persons by Florida medical

304 examiners. Florida Department of Law Enforcement; 2017.

305 3. Centers for Disease Control and Prevention. HIV surveillance report, 2018

306 (Preliminary); vol. 30. http://www.cdc.gov/hiv/library/reports/hiv-surveillance.

$307 \mathrm{html}$. Published November 2019. Accessed [1/31/2020]

308 4. Alex Wodak AC, World Health Organization. Effectiveness of sterile needle and syringe programming in reducing HIV/AIDS among injecting drug Switzerland: World Health Organization; 2004.

5. Centers for Disease Control and Prevention. Summary of information on the safety and effectiveness of Syringe Services Programs (SSPS) [Available from: https://www.cdc.gov/ssp/syringe-services-programs-summary.html. Accessed 1 Oct 2019.

6. AIDs UN. Do no harm - health, human rights and people who use drugs. 2016 April 152016.

7. Mars SG, Ondocsin J, Ciccarone D. Toots, tastes and tester shots: user accounts of drug sampling methods for gauging heroin potency. Harm Reduct J. 2018;15(1):26.

8. Reed M, Wagner KD, Tran NK, Brady KA, Shinefeld J, Roth A. Prevalence and correlates of carrying naloxone among a community-based sample of opioid-using people who inject drugs. Int J Drug Policy. 2019;73:32-5.
9. Chimbar L, Moleta Y. Naloxone effectiveness: a systematic review. J Addict Nurs. 2018:29(3):167-71.

10. Wheeler E, Jones TS, Gilbert MK, Davidson PJ. Centers for Disease Control and Prevention. Opioid overdose prevention programs providing naloxone to laypersons - United States, 2014. MMWR Morbidity and mortality weekly report. 2015;64(23):631-5. to lay bystanders: findings from a decade of naloxone distribution in 330 Pittsburgh. PA. J Psychoactive Drugs. 2018;50(3):240-6.

12. Giglio RE, Li G, DiMaggio CJ. Effectiveness of bystander naloxone administration and overdose education programs: a meta-analysis. Inj Epidemiol. 2015;2(1):10.

13. McDonald R, Strang J. Are take-home naloxone programmes effective? Systematic review utilizing application of the Bradford Hill criteria. Addiction. 2016:111(7):1177-87.

14. Olsen A, McDonald D, Lenton S, Dietze PM. Assessing causality in drug policy analyses: How useful are the Bradford Hill criteria in analysing takehome naloxone programs? Drug Alcohol Rev. 2018;37(4):499-501.

15. Alvarez L. Florida shutting 'pill mill' clinics. The New York Times. 2011.

16. Tookes H, Diaz C, Li H, Khalid R, Doblecki-Lewis S. A cost analysis hospitalizations for infections related to injection drug use at a county safety-net hospital in Miami. Florida. PLoS One. 2015;10(6):e0129360.

17. Rutkow L, Chang H-Y, Daubresse M, Webster DW, Stuart EA, Alexander GC. Effect of Florida's prescription drug monitoring program and pill mill laws on opioid prescribing and use. JAMA Internal Medicine. 2015;175(10):1642-9. 347

18. Keane C. Egan JE, Hawk M. Effects of naloxone distribution to likely 348 bystanders: results of an agent-based model. Int J Drug Policy. 2018:55:61-9. 349

19. BCHD. Jurisdictional plan for HIV prevention in Baltimore City. Baltimore 350 City; 2012. 2015.

\section{Publisher's Note}

Springer Nature remains neutral with regard to jurisdictional claims in (i)
323 (3) 32 333 334 (n)

Ready to submit your research? Choose BMC and benefit from:

- fast, convenient online submission

- thorough peer review by experienced researchers in your field

- rapid publication on acceptance

- support for research data, including large and complex data types

- gold Open Access which fosters wider collaboration and increased citations

- maximum visibility for your research: over $100 \mathrm{M}$ website views per year

At BMC, research is always in progress.

Learn more biomedcentral.com/submissions 